\title{
Code-Switching Makes Sense, $\mathrm{LO}^{1}$ ? Factors Involved in Code-Switching in a Multilingual Society
}

\author{
Orit Berlinsky-Shay \\ Alexandru Ioan Cuza University of Iaci, Iaci, Romania
}

\begin{abstract}
This paper presents the initial findings of an in-process study, which seeks factors involved in the phenomenon of code-switching in multilingual Israel, where one may find a significantly complex linguistic reality, in which 40 to 50 languages are spoken. The study examines instances of code-switching collected from three groups of participants, bilinguals of Hebrew and English, as well as bilinguals of Hebrew and Arabic. Data were collected by observations, recording and transcribing 25 hours of discourses at various occasions during the last 20 months. The first analysis of all data identifies 12 types of code-switching, e.g., reiteration, discretion, parenthetical clauses, and more. In this sense, the largest category is the one consists of "undefined" instances of code-switching, namely, those instances which fall under none of the recognizable types, as if the speaker switches to the other language as an unconscious act and for no obvious reason. Derived from this circumstance, a second analysis has been conducted, which examined the socio-linguistic, psycho-linguistic, professional, cultural, and grammatical factors involved in code-switching. This analysis shows that sometimes more than one factor is involved, and that there is no "just" code-switching. Speakers do not code switch purposelessly, some of the evidence to support that is the fact that in the presence of a monolingual interlocutor, the same speakers do not code switch. They simply realize that their partner will not understand them unless they make the choice to stick to one language. Since code-switching is a well-known trait in the speech pattern of the average bilingual in any human society all over the world, finding a model of code-switching in the multilingual reality existing in Israel may shed light on the phenomenon of code-switching in other countries with similar linguistic reality, as a large proportion of the world's population is bilingual.
\end{abstract}

Keywords: code-switching, bilingualism, multilingualism, socio-linguistics

\section{Introduction}

Back in 1947, Barker realized that in some interactions (e.g., among family members or other intimates), the conversations were more often conducted in Spanish; while in others (e.g., formal talk with Anglo-Americans), the spoken language was English, even when all parties in the interaction were able to understand Spanish. He was interested in answering the question, "How does it happen, for example, that among bilinguals, the ancestral language will be used on one occasion and English on another, and that on certain occasions, bilinguals will alternate, without apparent cause, from one language to another?" (1947, pp. 185-186).

Orit Berlinsky-Shay, a doctoral student, Department of Letters, Alexandru Ioan Cuza University of Iaci.

1 "LO" is the Hebrew word for "no". 
This paper presents a research conducted in the multilingual reality of Israel, examining the linguistic phenomenon of code-switching among bilinguals, speakers of Hebrew and English, as well as Hebrew and Arabic. The different parts of the paper include a brief review of literature, the gap in knowledge which motivated this study, the research design and methodology, and finally - the findings arising from two separate analyses of all instances of code-switching and information collected via observations and interviews.

\section{Brief Review of Literature}

As the linguistic phenomenon in question is called code-switching, it should firstly be clear what the term "code" refers to. Auer (1998) noted that the question of what counts as a code is not easy to answer, since it is the participants who determine what a code is, and not the linguists. Moreover, he raised the question, "How can we, the analysts, prove that a given set of co-occurring linguistic features is perceived by participants as a distinct code?" (Auer, 1998, p. 13). The only answer to this question, claimed Auer, is by showing that switching between this set and another is employed in a meaningful way in bilingual conversation.

When a particular code is decided on, there is no need to stick to it all the time, as can be seen in the instances of code-switching presented in the current study. People can and should shift, as the need arises, from one code to another (Wardhaugh, 2010). In everyday interaction, people usually choose different codes in different situations. They choose a particular code or variety to discuss a particular topic, taking into account various dimensions, such as social distance, status relationship, formality, goal of interaction, and more. When talking about school or work at home, for instance, one may use the language that is related to those fields rather than the language used in daily language communication at home (Holmes, 2013). In the present study, the term "code" refers to a language.

The phenomenon of code-switching has gained great attention and different researchers related to it in different ways. Code-switching has developed from what used to be looked upon as "possibly a somewhat peculiar act" (Luckmann, 1983) into a subject matter which enlightens fundamental linguistic issues, from universal grammar to the consolidation of identities and ethnic boundaries through verbal behavior. Although the scholarly literature offers different definitions for the term "code-switching," it is used in the current study as a general term to cover all aspects of code alternation between two different languages, the switching between Hebrew and Arabic and the switching between Hebrew and English.

Code-switching is a widespread phenomenon in bilingual speech, and it is therefore not surprising that a great proportion of research on bilingualism focuses on this topic (Riehhl, 2005). The ownership of two or more languages is increasingly seen as an asset as the "communication world" gets smaller (Baker, 2011). Phenomena, such as globalization, modernization, and language revival have increased the number of people speaking more than one language (Milroy \& Muysken, 1995).

Auer (1995) explained that code-switching "is defined as a relationship of contiguous juxtaposition of semiotic systems, such that the appropriate recipients of the resulting complex sign are in a position to interpret this juxtaposition as such" (p. 116). This definition implies that such phenomenon may take place only between participants who fully understand the two systems which are in contact, namely, bilinguals.

Although some researchers (e.g., Fabbro, 1999) distinguish between bilinguals and multilinguals, claiming that the first speak two languages whereas the latter speak more than two languages, there are some others (e.g., Wei, 2013) who claim that both phenomena refer to the coexistence, contact, and interaction of different languages in society or in an individual, an attitude which was espoused in this study. 
In the last decades, developments, such as massive population shifts through migration, the expansion of educational provision to many more levels of society, and technical advances in large communities have emphasized the existence of a visibly and audibly multilingual modern world (Milroy \& Muysken, 1995).

To the average person in the United States or Europe, bilingualism - the regular use of two or more languages - is a rather special language phenomenon restricted to a few countries, such as Canada, Belgium, or Switzerland, where every citizen is bilingual (Grosjean, 2001). However, to a citizen of Israel, bilingualism is the norm; most people speak two or more languages. Multilingualism has always been common in the Israeli reality. In Jerusalem, for example, at the end of the 19th century, Arabic, Turkish, Greek, Yiddish, English, German, Latin, and Aramaic were in use. Many people, especially those living in the cities, were bilingual (Spolsky \& Cooper, 1991).

At present, the population in Israel is divided into a Jewish majority and a big Arab-speaking minority, amounting about $20 \%$ of the population. The Jewish sector itself, while in principle Hebrew-speaking, is only partly composed of native speakers of the language. As an immigrant society, Israel includes a large percentage of native speakers of a variety of other languages, whose share in the population periodically increases due to waves of mass immigration from various parts of the world (Spolsky \& Shohamy, 1999).

According to the Israel Bureau of Immigration and the Jewish Agency, a record number of 29,500 new immigrants arrived in Israel in 2014, most of them from the former Soviet Union $(14,100)$ and from Europe $(9,000)$. Three thousand and six hundred immigrants arrived from North America and 1,200 from Latin America. The two leading countries in relation to the number of immigrants are France and Ukraine. In addition, 690 people arrived from Britain, 400 from Italy, and 290 from Belgium.

In private, Israelis speak 40-50 languages they have brought to Israel as immigrants, and their discourse if full of utterances and phrases in the languages of the different countries which made up the Jewish Diaspora. Complex patterns of code shifting between these languages and Hebrew are very common, especially among older people who are still monolingual living with the younger generations who are now native speakers of Hebrew.

\section{Gap in Knowledge}

Code-switching is a well-known phenomenon, mainly practiced by bilinguals. In the unique linguistic reality of Israel, both Hebrew and Arabic have a status of official language. Nevertheless, English is given precedence over Arabic in many contexts; it is a compulsory subject of study from elementary school through graduation, and an essential subject in the matriculation exam. There are only few researches discussing what factors are involved in code-switching in such circumstances.

\section{Research Design and Methodology}

Since this research examines a linguistic phenomenon and its relations with socio-linguistic, psycho-linguistic, cultural, grammatical, and professional factors, the method chosen for it was the qualitative one. Within the qualitative method, the research used the discourse analysis. Discourse analysis is an increasingly popular qualitative research method in social sciences (Cameron, 2001). The process of discourse analysis usually involves two instances of transformation: in the first one, discourse is "collected" via a recording device; and in the second one, recording is transformed into some kind of written or multimodal artifact for the purpose of analysis (Jones, 2011). 


\section{Research Questions}

The main research question was: What patterns of code-switching can be identified within Israeli society as a multilingual reality?

Derived from this general question, three secondary question have risen:

1. In what circumstances do people in Israel code-switch?

2. What grammatical, socio-linguistic, cultural, psycho-linguistic, and/or professional factors are involved in code-switching between Hebrew-English and Hebrew-Arabic?

3. What are the causes of code-switching (e.g., idleness, family composition, convenience, and schooling)?

\section{Research Participants}

Since the present research examines the phenomenon of code-switching among Israeli bilingual speakers of Hebrew, English, and Arabic, it includes there groups of study:

Group 1: Nine high school English teachers; all of them are bilingual, but the matrix language (i.e., the dominant language) varies between them.

Group 2: Five family members; the mother is an American English speaker, the father is an Israeli Hebrew speaker. The couple has two daughters: The elder one is 29 years old, married to an American English speaker, and the younger one is 25 years old. All family members speak English and Hebrew alternatively.

Group 3: Nine construction workers who work at a construction site in Tel-Aviv, Israel. The workers are all bilingual men, speakers of Hebrew and Arabic.

\section{Research Tools}

Within the framework of the discourse analysis, the research includes several tools: participant observations and nonparticipant observations of all three groups, recording of discourses, transcribing of the parts which includes code-switching and analyzing all instances of code-switching. In addition, the research includes semi-structured interviews of some of the participants, in order to get some deeper impression and understanding about their need to code-switch.

\section{Findings}

The first categorization of the data collected identified 12 different kinds of code-switching:

1. Reiteration: The speaker switches to the other language for the actual sake of repeating or reiterating the word/phrase/sentence that was said inthe first language.

2. Discretion: The speaker switches to the other language in order to say something personal, meant only for the ears of a specific person from the crowd of listeners.

3. Addressing a specific attender: The speaker switches to the other language when addressing a specific person from the present audience, creating intimacy with one of the crowd, as if there are only the speaker and the interlocutor present, ignoring all other attendants.

4. Exclamation and expressing emotions: The speaker switches to the other language when exclaiming an utterance emotionally or strongly expressing a personal opinion which he/she wishes so stress.

5. Idioms and expressions: The speaker switches to the other language at the point of using a fixed expression, an idiom or a proverb in its original language, which carries an obvious meaning suiting the current situation. 
6. Professional and cultural terms: The speaker switches to the other language when using a term known to the present audience and/or general public in its original language and rarely if ever is translated. Mostly, it is a professional term used by a group of people from the same field, as found in Group 1 and in Group 3. In addition, the terms nay carry a cultural background, namely, they are known to people living in the linguistic culture of Israel.

7. Parenthetical clauses: The speaker switches to the other language in cases where it seems as if he/she is making a personal remark to himself/herself.

8. Tag questions: The speaker switches to the other language for a tag question, at the end of an utterance.

9. Connectors and transition words: The speaker switches to the other language using connectors (e.g., but in short) or transition words (e.g., namely, anyway).

10. Quoting: The speaker switches to the other language in order to quote what has been said by a third party. It should be noted that this type of code-switching was found only in the findings gathered from Group 2.

11. "Leading-to-switching" words: In these instances, it seems that the speaker switches to the other language saying a certain word or phrase, and then sticks to the "new" language for the rest of the utterance, and does not go back to the first language, with which he has started the utterance.

12. "Undefined" instances: This category was found to be the largest of all 12. It includes instances in which the researcher could find no obvious characteristic or pattern. Similarly to all the above-mentioned categories, these code-switching instances could appear in the beginning, in the middle, or at the end of the utterance and consist of a word, a phrase, or a sentence. However, they do not seem to suit any of the cases above, since they carry no reasonable cause on the part of the speaker to code-switch.

Not all 12 categories were found to be significant, considering the level of frequency of their occurrence. This frequency can be seen in Table 1.

Table 1

Frequency of Categories Amidst All Groups of Participants

\begin{tabular}{lccc}
\hline Category & Group 1(\%) & Group 2 (\%) & Group 3 (\%) \\
\hline Undefined & 30 & 47 & 36 \\
Professional and cultural terms & 9 & 14 & 32 \\
Reiteration & 7 & 7 & 18 \\
Connectors and transition words & 13 & 4 & 0 \\
Exclamations and expressing emotions & 9 & 7 & 0 \\
Addressing a specific attender & 12 & 4 & 0 \\
Leading-to-Switching words & 4 & 0 & 11 \\
Idioms and expressions & 5 & 4 & 0 \\
Discretion & 6 & 2 & 0 \\
Quoting & 0 & 7 & 0 \\
Parenthetical clauses & 4 & 2 & 0 \\
Tag questions & 1 & 4 & \\
\hline
\end{tabular}

Focusing on the five most frequent types of code-switching amidst all three groups of participants, Table 1 shows that these are:

1. Undefined instances of code-switching (the first in all groups);

2. Professional and cultural terms (one of the first five in all groups);

3. Reiteration (the third in both Group 2 and Group 3); 
4. Connectors and transition words (only in Group 1);

5. Exclamations and expressing emotions (the fourth in both Group 1 and Group 2).

Some interesting findings should be pointed out regarding this categorization, and the following clauses will discuss the most prominent ones.

1. Both Group 1 and Group 2 practiced 11 out of the 12 identified categories of code-switching; however, Group 3 practiced only five of them. This may suggest that due to unknown circumstances and causes, the speakers of Hebrew and Arabic demonstrated less than half of the different types of code-switching practiced by speakers of Hebrew and English.

2. A category which is very dominant in one group may be insignificant in another. For example, a type of code-switching located in the second place of frequency in Group 1 ("Connectors and transition words") is not practiced at all by participants of Group 3.

3. All groups of participants practice undefined instances of code-switching in the most frequent manner of all. In other words, the most common type of code-switching in all groups of participants showed no obvious pattern, unlike other types.

However, the idea that there is no apparent reason, pattern or drive for the speaker to alternate the language is almost as unreasonable as the speaker's switching from language A to language B. Determining that these instances are unreasonable contradicts the target of this research, which was to examine the factors motivating code-switching in the multilingual reality of Israel. Therefore, the next stage of analyzing the data included a new categorization according to the following factors: socio-linguistic, psycho-linguistic, professional, cultural, and grammatical. This thorough examination of code-switching instances among all three groups of participants determined that each and every instance involved one of the above factors, and even more than one. In other words, an instance which was previously identified as a case of "reiteration," for instance, was found as involving a socio-linguistic factor.

In the following example (where the capital letters represent Hebrew and later are translated in the square brackets), the English teachers are in the middle of a meeting, where the conversation is run in English. At one point, the head of English department (HED) mentions a specific occasion when R taught her students a unit which was not very important and consumed a great amount of time and energy. She wanted the rest of the staff to know that this specific unit is not worthwhile. $\mathrm{R}$ is addressing her colleagues by saying:

Ken, Ken, Ani Mitzta'arti She'asiti Et Ze, I regret doing it.

Yes, yes, I am sorry I did it. I regret doing it.

$\mathrm{R}$ is using the "reiteration" type of code-switching, but her aim is to emphasize the fact that she is really sorry for doing that (i.e., wasting time on teaching the unnecessary unit).

\section{Conclusions}

Going over the instances of code-switching one by one demonstrates that each one of them is involved with one or more of the factors. In this second categorization, it seems that no instance is left "undefined," unlike the findings of the first categorization.

Bilinguals perform the switching from language A to B and vice versa for a reason. They code switch, because they want to emphasize something; they need to express an emotion; they wish to challenge their interlocutor; they switch for a professional term that they always use in language B; they naturally switch to 
language B when they utter a remark to themselves as in parenthesis; they need a word which better expresses their idea and exists only in the second language, and so on.

One of the conclusions drawn from the second categorization is that among Group 1, the psycho-linguistic factor is the most dominant one, whereas among Group 2, it is the socio-linguistic factor, and among Group 3, it is the professional one. When examining all instances of code-switching from all three groups, the socio-linguistic factor is the most dominant one. In other words, in an overall view, most of the code-switching instances involve socio-linguistic considerations.

Another conclusion is that Group 1 practiced code-switching involving all factors, Group 2 did not practice any code-switching involving the professional factor, and Group 3 did not practice any code-switching involving the psycho-linguistic factor.

In addition, all instances of intra-sentential code-switching indicated a grammatical agreement between the main sentence and the part of the code-switching. In other words, when switching to language B in the middle of an utterance, the speakers never violated grammatical rules of language A. It seems, then, that bilingual do not really need grammatical constraints, as they master the rules of both languages and are perfectly aware of what switches are possible and which are not. They do not pause to weigh their next words, grammatically speaking, before they switch to the other language. On the contrary, one of the teachers who was interviewed admitted that she does a conscious decision, which demands great efforts on her part, to not switch to Hebrew whenever she speaks in English as a challenge she has set for herself. She claims that code-switching is the easy way, which she expects herself to overcome.

Nevertheless, based on data collected and analyzed in the framework of this research, it would be wrong to believe that code-switching is an unconscious act on the part of the speaker. When a bilingual conducts a conversation, he or she knows well that if their interlocutor shares their knowledge of the other language, they will let themselves code-switch, and if they are aware of the fact that their interlocutor is a monolingual, they will stick to the one language they share. All in all, code-switching is a language of its awn, created from bilinguals' art of combining existing languages. Regarding intra-sentential code-switching, bilinguals demonstrate knowledge of structures existing in both languages, which enables them to locate the switching in the appropriate and acceptable point in their utterance.

\section{References}

Auer, P. (1995). The pragmatics of code-switching: A sequential approach. In L. Milroy \& P. Muysken (Eds.), One speaker-Two Languages: Cross disciplinary perspectives on code-switching (pp. 115-135). Cambridge: Cambridge University Press.

Auer, P. (1998). Bilingual conversation revised. In P. Auer (Ed.), Code-switching in conversation (pp. 1-24). London \& New York: Routledge.

Baker, C. (2011). Foundation of bilingual education and bilingualism (5th ed.). USA: McNaughton \& Gunn Ltd..

Barker, G. (1947). Social functions of language in a Mexican-American community. Acta Americana, 5, 185-202.

Cameron, D. (2001). Working with spoken discourse. London: SAGE Publications Ltd..

Fabbro, F. (1999). The neurolinguistics of bilingualism: An introduction. New York: Taylor and Francis Group.

Grosjean, F. (2001). Life with two languages: An introduction to bilingualism. USA: Harvard University Press.

Holmes, J. (2013). An introduction to sociolinguistics (4th ed.). Oxon and New York: Routledge.

Jones, P. G. (2011). An Introduction to discourse analysis theory and method. London: Routledge.

Luckmann, T. (1983). Life-world and social realities. London: Heinemann.

Milroy, L., \& Muysken, P. (Eds.). (1995). One speaker, two languages: Cross-disciplinary perspectives on code-switching. Cambridge: Cambridge University Press. 
Riehl, C. M. (2005). Code-switching in bilinguals: Impacts of mental processes and language awareness. In J. Cohen, K. T. McAlister, K. Rolstad \& J. MacSwan (Eds.), ISB4: Proceedings of the 4th International Symposium on Bilingualism (pp. 1945-1959). Somerville, M.A.: Cascadilla Press.

Spolsky, B., \& Cooper, R. (1991). The languages of jerusalem. Oxford: Clarendon Press.

Spolsky, B., \& Shohami, E. (1999). The languages in Israel: Policy, ideology and practice. Great Britain: Cromwell Press Ltd.. Wardhaugh, R. (2010). An introduction to sociolinguistics (6th ed.). UK: Wiley-Blackwell.

Wei, L. (2013). Conceptual and methodological issues in bilingualism and multilingualism research. In T. K. Bathia \& W. C. Ritchie (Eds.), The handbook of bilingualism and multilingualism (pp. 26-52). UK: Wiley Blackwell. 